\title{
The role of Eastern approaches in David Bohm's scientific-philosophical odysseia
}

\section{Pylkkänen, Paavo}

2017-09-01

Pylkkänen , P 2017 , ' The role of Eastern approaches in David Bohm's scientific-philosophical odysseia ', Progress in Biophysics \& Molecular Biology , vol. 131, pp. 171-178 . https://doi.org/10.1016/j.pbiomolbio.2017.08.015

http://hdl.handle.net/10138/231581

https://doi.org/10.1016/j.pbiomolbio.2017.08.015

gnu_lgpl

draft

Downloaded from Helda, University of Helsinki institutional repository.

This is an electronic reprint of the original article.

This reprint may differ from the original in pagination and typographic detail.

Please cite the original version. 


\title{
The role of Eastern approaches in David Bohm's scientific- philosophical odysseia
}

\author{
Paavo Pylkkänen ${ }^{\mathrm{a}, \mathrm{b}}$ \\ a Department of History, Philosophy, Culture and Art Studies \& Academy of Finland Center of Excellence in the Philosophy of the Social Sciences, University \\ of Helsinki, Helsinki, Finland \\ ${ }^{\mathrm{b}}$ Department of Cognitive Neuroscience and Philosophy, School of Bioscience, University of Skövde, Sweden
}

\section{A R T I C L E I N F O}

\section{Article history:}

Received 1 July 2017

Received in revised form

23 August 2017

Accepted 28 August 2017

Available online $\mathrm{xxx}$

\section{Contents}

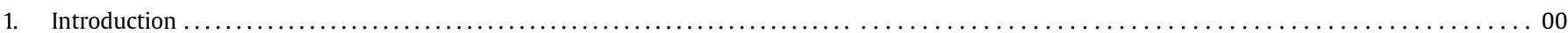

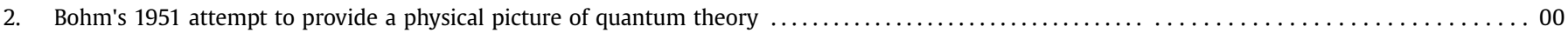

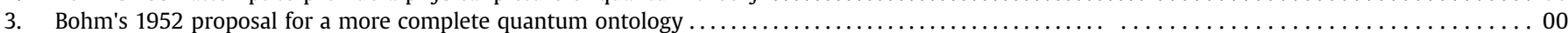

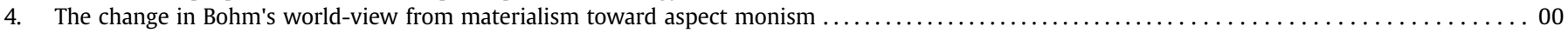

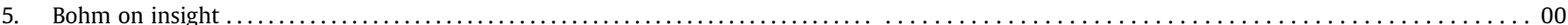

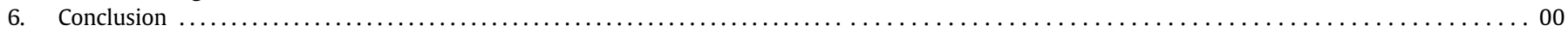

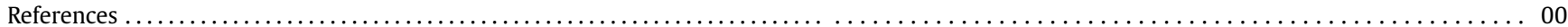

\section{Introduction}

The physicist David Bohm (1917-1992) is one of those Western scientist-philosophers whose thinking was strongly influenced by encounters with Eastern thought, in particular with J. Krishnamurti and to some extent also with the Dalai Lama. In this article we will explore some ways in which this influence expresses itself in Bohm's work. We will see that Bohm's early scientific metaphysics, inspired by quantum theory, had strongly holistic and relational features even before his encounters with the East. This is yet another indication that there are important analogies between modern physics and some aspects Eastern philosophy, as has been emphasized by Capra (1995). However, we will also suggest that Bohm's encounter with Krishnamurti played a key role in the process in which his worldview changed from dialectical

E-mail addresses: paavo.pylkkanen@helsinki.fi, paavo.pylkkanen@his.se. materialism toward a more comprehensive view, where concepts such as information and meaning play a fundamental ontological role. Also, as an important example of the way Bohm's thinking was influenced by Krishnamurti, we will focus upon Bohm's notion of insight.

The structure of the paper is as follows. Section 2 considers Bohm's early ideas, presented in 1951 when he was still working in the framework of the usual interpretation of quantum theory. Section 3 briefly presents and discusses Bohm's 1952 "hidden variable" interpretation of quantum theory, and section 4 considers the way Bohm's world-view changed from the late 1950s onwards toward a more idealist direction, while remaining a form of scientific realism. Finally, section 5 discusses Bohm's notion of insight and some related issues, such as fragmentation.

\section{Bohm's 1951 attempt to provide a physical picture of quantum theory}

Bohm started out his career as a quantum physicist and was dissatisfied with the prevailing tendency to assume that quantum theory cannot be understood in an imaginative sense. The 
mainstream assumed that the theory has to be interpreted in an instrumentalist way, as a mathematical formalism that can predict the results of experiments, but that cannot provide an intelligible picture of the quantum world. Thus a major part of Bohm's acclaimed 1951 textbook Quantum theory was an attempt to provide also a physical (over and above a merely mathematical) formulation of the theory.

Bohm emphasized in particular the holistic implications of quantum theory. Classical physics essentially involved features such as continuous and precisely defined trajectories, rigid determinism and the primacy of individual systems that have an intrinsic nature. In contrast, quantum theory described motion in terms of a series of indivisible transitions ("quantum jumps"), saw causality as an approximate and statistical trend and emphasized that individual systems do not have a fixed nature, but can act either as waves or as particles, depending on the nature of the surrounding environment.

Classical physics had given rise to a strongly atomistic ontology, in which "... the world can correctly be analyzed into distinct parts each having a separate existence, but working together according to exact causal laws to form the whole" (Bohm, 1951: iv). In this view, the parts are prior to the whole, and the whole is just a convenient way of talking about the parts and their interactions. In contrast, Bohm argued that "... quantum concepts imply that the world acts more like a single indivisible unit, in which even the 'intrinsic' nature of each part (wave or particle) depends to some degree on its relationship to its surroundings" (1951: iv). This view emphasizes monism in the sense of the priority of the whole (cf. Schaffer, 2010). It also resonates with contemporary ontic structural realism, where it is assumed that relationships are ontologically more fundamental than individual objects and their intrinsic properties (cf. Ladyman and Ross, 2007). Note that, as we already pointed out in the introduction, Bohm had arrived at a strongly holistic and relational view about the nature of being on the basis of quantum theory, before any significant interaction with Eastern thought.

Another aspect of Bohm's 1951 book Quantum theory worth noting in this context is the section "Analogies to quantum processes" (pp. 168-172; see also Pylkkänen, 2014). He there draws attention to a number of striking resemblances between quantum processes and thought. For example, he suggests that a kind of uncertainty principle applies to thought in the sense that "... if a person tries to observe what he is thinking about at the very moment that he is reflecting on a particular subject, it is generally agreed that he introduces unpredictable and uncontrollable changes in the way his thoughts proceed thereafter" (1951: 169). This implies a kind of interdependence between the observer and the observed in the psychological domain that resonates with one of Krishnamurti's key proposals, namely that in the psychological domain "the observer is the observed". It is striking that Bohm had considered these kinds of issues almost ten years before his encounter with Krishnamurti's ideas in 1959. This perhaps explains partly why Bohm responded to Krishnamurti's teachings with such enthusiasm and passion. He may have recognized in Krishnamurti's views about consciousness echoes of the kind of wholeness and relationality that seemed to be so evidently present in the quantum theory. As Wheeler (1990) has emphasized, in the quantum domain the observer is a participator, and it seems evident that we find such participation of the observer in what is observed also in the psychological domain of introspection (see also Wang et al., 2013). We live in a participatory universe, both (quantum) physically and psychologically.

\section{Bohm's 1952 proposal for a more complete quantum ontology}

Bohm's aim in writing the 1951 book had been to come up with a physical formulation of the quantum theory. However, after writing the book he still felt somewhat dissatisfied. He says that the main problem was not indeterminism but rather that the theory could not provide a coherent ontological story about the quantum world (Bohm, 1987):

"What I felt to be especially unsatisfactory was the fact that the quantum theory had no place in it for an adequate notion of an independent actuality, that is, of an actual movement or activity by which one physical state could pass over into another one. My main difficulty was not that the wave function was interpreted only in terms of probabilities, so that the theory was not deterministic. Rather, it was that it could only discuss in terms of the results of an experiment or an observation, which has to be treated as a set of phenomena that are ultimately not further analyzable or explainable in any terms at all. So, the theory could not go beyond the phenomena or appearances. And basically, those phenomena were very limited in nature, consisting, for example, of events by which the state of a particle could be ascertained. From a knowledge of this state, we could go to a wave function that predicted the probability of the next set of phenomena, and so on."

So while it is common to think that Bohm was primarily hoping for a return to strict determinism, he himself says that he wanted to find a more complete quantum ontology, a description of what is taking place at the quantum level beyond the appearances, and also independently of whether or not a measurement is taking place (for a discussion of the question of appearance vs. reality in the quantum domain, see Pylkkänen, 2015). In the meantime Einstein had read Bohm's 1951 book and wanted to discuss with him, which was easy to arrange as the two of them were in Princeton at the time. As is well known, Einstein thought that quantum theory is incomplete, and strongly encouraged Bohm to search for an ontological and deterministic description of quantum reality.

Bohm soon discovered an interpretation of quantum theory that provides such a description (Bohm, 1952; see also Goldstein, 2013). In fact, he had rediscovered and formulated more coherently the pilot wave theory which de Broglie had presented in the 1927 Solvay conference (see Bacciagaluppi and Valentini, 2009; see also Holland, 2011; Bell, 1987) Ironically, Bohm's 1952 theory restores at the quantum level many of the features of classical physics that Bohm in his 1951 book had said quantum theory overthrows.

According to the Bohm theory an electron is a particle always accompanied by a new type of field which gives rise to a new kind of quantum potential $Q$. This means that the behavior of the particle is influenced not only by classical potentials but also by the quantum potential. The difference between classical and quantum behavior is due to the effect of the quantum potential. In circumstances when the quantum potential has a negligible effect, classical physics provides a good approximate description. All this makes it possible to conceive of an electron as a particle that is moving continuously and deterministically along a trajectory. When the quantum potential is non-negligible the trajectories are non-classical, while when the quantum potential is negligible the trajectories become classical for all practical purposes.

However, unlike what is sometimes suggested, Bohm's theory is not a return to classical physics, for the quantum potential has a 
number of non-classical features. First of all, it generally provides a non-local interaction between particles; it is only when the wave function becomes factorized that we can restore locality (the classical limit). While Bohm's theory is experimentally consistent with relativity, its non-locality suggests a preferred frame and creates a tension with relativity. This is presumably one of the reasons Einstein could not give his support to Bohm's hypothesis. However, experiments testing Bell's inequalities go against local hidden variable theories (which Einstein presumably was looking for), thus vindicating Bohm's theory (and standard quantum theory; see Aspect et al., 1982; Bricmont, 2016). Thus, while Bohm's theory restores some key classical features (in particular, particle trajectories), its non-locality underlines the primacy of wholeness, albeit in a different way than standard quantum theory (for a recent attempt to reconcile non-locality and relativity, see Walleczek and Grössing, 2016).

We saw above how standard quantum theory implies that individual quantum objects do not have a fixed intrinsic nature but can act either as waves or as particles, depending on the nature of the surrounding environment. The Bohm theory postulates that electrons are particles, so does this mean that it restores individual objects with intrinsic properties at the quantum level? This is a subtle question which has been subject to some debate during recent decades. One important issue here is that the quantum potential can be large even when the amplitude of the quantum field is weak. This makes possible a kind of non-locality in the sense that distant features of the environment (e.g. the presence of slits) can have a profound effect upon the behavior of the particle. Thus because of the influence of the quantum potential, the behavior of the particle is strongly dependent upon its surrounding context, emphasizing wholeness and relationality. But are we still allowed to assume that the electron is a particle with intrinsic properties? Experimental evidence (e.g. neutron interferometry and the Aharonov-Bohm effect) implies that it does not seem to be possible to attribute properties such as mass and charge entirely to the particle aspect of the electron; the wave function also seems to play a role here (for discussion, see, Pylkkänen et al., 2016 and the references therein). Thus, while it seems at first sight that the Bohm theory restores the possibility of taking individual particles as fundamental at the quantum level, a more careful examination reveals that Bohmian particles are context-dependent in a highly non-classical way. So, rather than being a return to classical physics, one could argue that the Bohm theory actually brings out the nonmechanical features of the quantum world in a particularly explicit and clear way.

\section{The change in Bohm's world-view from materialism toward aspect monism}

We have seen that Bohm's quantum view of the physical world contained some radically holistic and relational features. If relationality is taken as fundamental, as in Ladyman and Ross's (2007) ontic structural realism, this can mean that one gives up materialism in any traditional sense. However, while Bohm emphasized the relational aspects of quantum reality already in 1951, it seems that his world-view remained materialist during the 1950s, when he was developing his 1952 theory further. In 1957 he published a philosophical book Causality and Chance in Modern Physics. A key proposal of the book was that nature is qualitatively infinite. This proposal was meant as an alternative to mechanistic materialism where one may admit quantitative infinity, but assumes in a mechanistic fashion that there is a fundamental level of basic elements that act according to fundamental laws to constitute the whole (cf. Schaffer, 2003). However, it seems that when it comes to ontology Bohm's Causality still remained within an overall (dialectical) materialist outlook. But in the late 1950s and early 1960s his thinking began to transcend traditional materialism and to move into new directions. One factor here is his reading of philosophers such as Hegel and Whitehead (see Peat, 1997). But it is very likely that his encounter with Krishnamurti's (1954) ideas in 1959, and the many subsequent discussions with him until the mid1980s played a key role in the unfolding of these new developments (e.g. Krishnamurti and Bohm 1999; Bohm (KFA)).

The focus of the discussions between Bohm and Krishnamurti was on the human condition. Krishnamurti had proposed that a major factor behind the problems of the world is our ignorance of the nature of our thought processes. Thought is a very powerful factor in our lives, but we do not observe and understand its actual operation and consequences properly and thus cannot control it. We are deeply conditioned and typically not aware of this. Krishnamurti suggested that a certain kind of meditation could allow intelligence and insight to operate upon thought and bring it into order, which would reflect itself in greater harmony and coherence at the social level.

The impact of the discussions with Krishnamurti is evident in many of Bohm's writings which deal with communication, dialogue and psychological questions (see e.g. Bohm and Edwards, 1991; Bohm, 1994, 1996; see also Isaacs, 1999; Senge, 2006). However, it is not so clear whether Krishnamurti influenced Bohm's views in physics and philosophy. Some indication that there was influence even in these areas is provided by the extensive correspondence Bohm had with the American structurist artist Charles Biederman (the first part of which is published, see Bohm and Biederman, 1999). Consider, for example, the following extract from a letter from Bohm to Biederman on the 20th of September 1962.

"The idea of a being which is in essence movement was exciting. [...] But later, I sought this in science, and saw that in the quantum theory, what was measured was an operator. To me, this signified a movement. Once again, this suggested to me a being that was movement. On reading about this, I felt myself as nothing but a movement, not divided from the universal movement but part of it. It was however many years before I could make much more progress in this direction. Only in the last two years have I been really learning something. And here, this "friend" to whom I referred in an earlier letter played a crucial part..." (The David Bohm Papers, The Library, Birkbeck, University of London, UK).

It becomes clear as the correspondence unfolds that the "friend" is Krishnamurti. The above was written during the period when Bohm had begun to discuss the notion of order in art and science with Biederman (see Bohm and Biederman, 1999). As is well known this concern with order led later on to the development of Bohm's notion of implicate order (and the associated notions of explicate and generative order and the dynamic notion of the "holomovement"; Bohm, 1980a, Bohm and Peat, 2000).

The above extract indicates that Krishnamurti inspired Bohm to start developing ideas such as the notion of (holo)movement as fundamental. It seems like Bohm was thinking along such lines all along, but Krishnamurti somehow gave a new force to the approach. There is a great deal of discussion about topics like the "ego process" in the Bohm-Biederman correspondence, so even this correspondence suggests that the main focus of the KrishnamurtiBohm interaction is on issues such as psychological liberation, rather than on more philosophical or physical ideas about movement. But it can be argued that Bohm's notion of the holomovement is not merely a concept in physics but also an attempt to give a scientific description to the sort of thing (the "whole", the "totality") Krishnamurti said we encounter or become when thought and 
mind become still. More generally, it is likely that discussions with Krishnamurti helped Bohm to become freer from traditional materialist thinking habits, and in this way to develop radically new general concepts and a new, less materialistic view of reality enabled by these concepts.

So what is the implicate order? We cannot here provide a full description, so just provide a brief illustration (cf. Jammer, 1988). We are all familiar with the explicate order of things in 3-dimensional space - tables and chairs and the like. The explicate order fits well with a mechanistic view in which we assume that reality is made of some fundamental elements (particles and/or fields) which interact mechanically to constitute the whole of reality. Bohm argued that both relativity and quantum theory strongly challenge the mechanistic order and instead suggest that what is fundamental is "undivided wholeness". In quantum theory we meet such wholeness in features such as wave-particle duality and entanglement. But our traditional mechanistic notions of order are not suitable to describe undivided wholeness, and thus a new notion of order is needed. He emphasized that to develop such a new notion of order is a major challenge for human understanding, a challenge that the implicate order tries to meet. The word "implicate" means literally enfolded. One aspect of the idea is that the whole is enfolded in each part. This is illustrated by the hologram, where the interference pattern at each part of the holographic plate enfolds information about the whole scene that was photographed. By shining light in a suitable way to any part of the plate, an image of the whole can be restored.

Bohm realized that in the quantum theory the wave function evolves in time in a movement of unfolding and enfolding. Such ideas led to a view of cosmology, where the universe (including space-time) unfolds from an enfolded state in a pre-space or implicate order. In a somewhat Whiteheadian matter Bohm proposed a process ontology, in which there is an underlying "holomovement" which undergoes constant unfoldment and reenfoldment. This movement is often recurrent and stable, and can give rise to space, time and particle-like manifestations - the explicate order that we find in ordinary experience. In later work Bohm would emphasize the active role of information and meaning even at the quantum level (Bohm, 1989; Weber, 1987), and proposed a theory of the relation of mind and matter (Bohm, 1990; Hiley and Pylkkänen, 2005; Pylkkänen, 2007a, 2017a). With Basil Hiley he provided a re-interpretation of Bohm's 1952 theory where the quantum potential was seen as containing active information (Bohm and Hiley, 1984, 1987, 1993; for the potential relevance of this idea to panpsychism, see Pylkkänen forthcoming; see also Seager, 2013; Seager and Allen-Hermanson, 2015; Strawson, 2006a, 2006b; Maleeh and Amani 2012). The implicate order theory and Bohm and Hiley's new version of Bohm's 1952 theory imply giving up traditional materialism as fundamental; but these theories are not idealism in the sense that the reality of a material aspect of reality would be denied. It seems reasonable to characterise Bohm's metaphysical view as a form of aspect monism: there is a unified underlying reality and the mental and the physical are different aspects of this reality rather than separate substances (see Atmanspacher, 2014). We will not here discuss the details of Bohm's later ideas, but repeat that it is very likely that they were in part inspired by his many discussions with Krishnamurti.

\section{Bohm on insight}

One concept for which it is clear that discussions with Krishnamurti influenced Bohm's thought is that of insight. Let us thus, as an example, examine Bohm's views about insight in some more detail. Here's how Bohm characterizes the concept: “...insight is an act, permeated by intense passion, that makes possible great clarity in the sense that it perceives and dissolves subtle but strong emotional, social, linguistic and intellectual pressures tending to hold the mind in rigid grooves and fixed compartments, in which fundamental challenges are avoided." (Bohm, 1980b: 60)

This short characterization reflects many of the issues that were explored by Krishnamurti and Bohm. The "rigid grooves and fixed compartments" of the mind are an example of the conditioning that Krishnamurti was drawing attention to. And the whole idea of insight bringing about clarity exemplifies the kind of transformation of the human mind that it was the mission of Krishnamurti to help to bring about.

Bohm was one of the speakers in a symposium "Knowledge, Education and Human Values", held in June 1980 at Woodstock, Vermont, USA. His 1981 article "Insight, Knowledge, Science, and Human Values" which was published in the proceedings of the symposium contains a succinct overview of some of his ideas about insight. In this section 1 will thus follow his line of thinking in that paper and summarize and discuss some of the key points.

Bohm first draws attention to the separation of knowledge and values in modern times and the way that this separation has affected the meaning and purpose of education. In science this separation has not only encouraged an irresponsible use of knowledge, it has also contributed to a general loss of meaning in life as a whole. This connects with the modern scientific world view, where the universe is pictured

“... as a vast space full of dead matter moving mechanically, while man is a tiny creature living on a mere speck of dust in this space, trying desperately make his life seem worthwhile by projecting his own arbitrary and inevitably petty ends and goals.“ (1981: 380)

This is a vivid description of the way in which our scientific world-view provides the context in which human life and action gain - or lose - their meaning. Bohm's diagnosis is in some ways similar to that of the Finnish philosopher Georg Henrik von Wright (1989). Von Wright, too, was concerned about the way in which the kind of scientific rationality connected with the mechanistic worldview might facilitate an exploitative and destructive attitude toward nature, resulting in a crisis of reason (see Pylkkänen, 2017b).

Bohm, however, was keen to point out that it is not inherent in science that it should lead to such a crisis of meaning. The problem is our fragmentary attitude toward knowledge. The challenge, then, is whether one might be able to change this attitude. Discussions with Krishnamurti had made Bohm aware of how deeply the human mind is conditioned. In the context of the mechanistic scientific world-view such conditioning expresses itself as mechanistic thinking habits that we need to overcome both in quantum and relativity physics and in our social interactions (cf. Wendt, 2015).

As a result of discussions with his research student Donald Schumacher, Bohm's philosophy took a linguistic turn in the 1960s. He started asking whether the subject-verb-object structure of Indo-European languages might facilitate a fragmentary attitude to reality. Further, as an experiment, he developed a new mode of language, the rheomode, in which verbs were given a primary role (Bohm 1980a, ch 2). The idea was that such a "flowing" mode of language might help us to better conceive of and describe both the indivisible quantum processes as well as the wholeness that prevails between the observer and the observed in the psychological domain in introspection. While Bohm's work on language has by and large been ignored by professional linguists and philosophers 
of language, some researchers have emphasized its truly revolutionary nature (see Stamenov 2004; see also Pylkkänen, 2007b).

In his 1981 article Bohm also discussed the nature of knowledge. He notes that knowledge is not merely abstract and passive (e.g. in books), but it is also active, in the form of skills and tacit knowledge. Active knowledge also involves our set of beliefs, which are based on presuppositions - a kind of active knowledge in us which we typically are unaware of. He illustrates this by an example. Imagine that you are walking along road which you presuppose to be level. Such a presupposition gives rise to an overall disposition of the body which is suitable for such a level road. Then suppose that there appear potholes in the road. You now need to drop your disposition in order to be able to walk properly. Bohm then uses this example as a metaphor for the way our beliefs influence our entire lives:

"Our whole approach to life is evidently full of presuppositions, which deeply affect not only our actions, but also our thoughts feelings, urges, desires, motivations, the content of the will, and, indeed, our general way of experiencing almost everything." (Bohm, 1981: 381)

Note here how he emphasizes the interdependence of the various aspects of the mind.

As an example of the power of our presuppositions he suggests that if we presuppose that certain kinds of people are inferior, we are very likely to actively perceive, experience and treat them as inferior. In philosophy of science it is typical to speak of "theoryladeness" of observation (e.g. Hanson, 1958), and Bohm here similarly draws attention to the way our presuppositions can profoundly influence our perceptions (rather than perceptions being able to neutrally inform our beliefs and presuppositions, as common sense suggests). While it has been fashionable in recent psychology to emphasize various such "top-down" effects, there are also important criticisms of a number of alleged "top-down" effects (see Firestone and Scholl, 2016).

He then further characterizes knowledge in a way that I find somewhat problematic. In particular he emphasizes that at any moment "knowledge is necessarily a mixture of what is correct and what is incorrect". However, in epistemology, knowledge is traditionally defined as "justified, true belief". Thus, Bohm's notion of "incorrect knowledge" does not quite make sense in the light of the common philosophical usage, where knowledge is by definition true belief. (However, in contemporary epistemology one no longer requires that knowledge always has to be absolutely true, which in a way makes it closer to Bohm's view.) In view of the fact that this traditional usage is widespread, it might have been better of Bohm to say that our set of beliefs is typically a mixture of what is correct and what is incorrect. Thus, when reporting his views below, I will at times use the expression "set of beliefs" in places where he himself uses "knowledge". While he makes some interesting points in his further discussion of knowledge, I will not report them in detail here.

Bohm emphasizes that experience is typically a whole process, a fusion of perception and knowledge. Often the contribution of perception can be assimilated within the general framework of past knowledge. However, sometimes challenges arise that require a genuinely creative and original response, going beyond the field of the known. Such a response is insight, which Bohm suggests is a crucially important issue not only in science or education but also in life as a whole. By insight Bohm refers to an inward perception perception through the mind. There are two senses in which insight is inward. On the one hand insight involves looking into the content of the mind - whatever it is that we are trying to understand. But on the other hand insight also has to involve looking into the very mind itself that is engaged in the act of knowing and understanding.
In contemporary terms we would say that insight involves a certain kind of meta-cognition, namely a cognition or perception of the mind as a whole, not merely an awareness of the contents of the mind. This is interestingly similar to Kant's notion of selfawareness, although I will not pursue the similarity here (see Brook, 1994). The above emphasis on the need to observe not only the content but also the process of thought also strongly reflects Krishnamurti's approach. Also, the idea that we need to go "beyond the field of the known" resonates strongly with Krishnamurti's teachings, where one of the central claims is that knowledge is always limited, which is meant as a criticism of the idea that knowledge alone could help humanity to solve its problems.

Bohm connects insight with the challenge of the contemporary breakdown in human values, which has various serious negative consequences. He suggests that we cannot rely upon existing knowledge here, but need insight to be able to come up with the appropriate new forms of response that can meet this challenge.

While science is partly responsible for the current crisis in values, Bohm nevertheless thinks that the history of science can teach us important things about the nature of insight. He notes that the meaning of insight is especially well illuminated by considering scientific theories which involve universal laws that apply for the totality of matter, independently of conditions of time and space. Such theories connect with notions of what he calls universal order. The basic notion which Medieval Europe inherited from the ancient Greeks was the idea that there is an order of increasing perfection between the earth and the heavens. The perfection of celestial matter was expressed in circular orbits, while the imperfection of earthly matter was expressed in the irregular motions on the surface of the earth.

Now, observations showed that the planets do not actually move in circles. But, Bohm notes, instead of changing their notion of universal order, the Greeks accommodated these observations by describing the movements of the planets in terms of epicycles (circles superimposed on circles). However, while such accommodation was useful, he suggests that it was also, in effect, a way to evade the challenge to the prevailing notion of universal order. One factor here was that the Greeks gave higher value to reason than to sense experience, which latter they considered unreliable. However, he suggests that the key point here is that our set of beliefs is an active process, which involves not only abstract thought, but also desire, will and action (I have here used the term "set of beliefs" instead of Bohm's "knowledge" for the reason mentioned above). And notions of universal order play a key part in such activity, not only because they give rise to positive feelings but also because questioning them is taken as a fundamental threat. The result is that we are reluctant to question such notions, which makes us prone to uncritically accept various adaptations of conflicting evidence.

The modern scientific approach involved a major change of attitude, in that observation, experience and experiments were given at least an equally high value as the faculty of reason. The key factor of the scientific approach is that the content of observation or perception may constitute a challenge to previously accepted presuppositions and beliefs, including those involving universal order. It is interesting to compare and contrast Bohm's above views with both Kuhn's notions of paradigm and anomalies, as well as Popper's notion of falsification as a key aspect of science; however we will not pursue such comparison here (but see Bohm and Peat, 2000).

Bohm next points out that with the application of the scientific approach, evidence was obtained suggesting that celestial and earthly matter are basically similar in nature (e.g. Copernicus's idea that the sun is the center of the planetary system; Kepler's idea that the planetary orbits are ellipses; and telescope observations showing irregular mountains on the moon). The implication of 
these results was that all matter is similar, regardless of its position relative to the earth. Yet, he suggests, people were not properly aware of how this new knowledge challenged the traditional view of matter.

Bohm notes that the above provides a background against which we can understand Newton's idea of universal gravitation as an outcome of a major insight. Newton was sensitive to this whole problem situation. The way he came to his insight was when he saw an apple falling. He then came up with the question: "Why doesn't the moon fall?"

"His answer was that the moon is falling, and indeed, because all matter is basically of the same nature, every such free body is falling toward every other, thus implying a universal force of gravitational attraction, similar to that experienced on the surface of the earth. Then he had to ask himself a second question. 'Why doesn't the moon ever reach the ground?' He explained this by the fact that it was in motion in an orbit, which tended to keep it moving away as it fell." (Bohm, 1981: 384)

Note the key role of questions in Newton's discovery. This connects interestingly with the interrogative model of inquiry (e.g. Hintikka, 1999; Sintonen, 1990). Bohm notes that Newton had to supplement his answers with a hypothesis about how the force of gravity relates to the distance from the earth. It so happened that he found one fast (the inverse square law). However, had he failed he could have kept on trying until finding a correct one. Bohm emphasizes that the basic idea of universal gravitation is separate and independent of such hypotheses. He is thus keen to emphasize that Newton's discovery was not a hypothesis, but rather a flash of perception, or an insight (this is similar to insight as discussed in the psychological literature, by e.g. Sternberg and Davidson, 1996). According to Bohm, Newton perceived the following inference: "if all matter is basically the same, and if there is gravitation on the earth, there must be universal gravitation". Universal gravitation follows when one puts together the general rule (all matter is the same), with a particular set of observations (there is gravitation associated with matter here on the earth).

Bohm then characterizes the "quality of genius" in the light of this example. The key aspect of this quality is to be intensely interested in questioning what is commonly accepted, something he says amounts to true passion. Without such passion, however, the mind is limited to move within its habitual frameworks of thought. In this way the mind may feel comfortable, secure and respectable, but it is not capable of insight. Here again we note that Bohm's view of insight seems to be greatly influenced by Krishnamurti's approach.

What is striking about the example of Newton is that people, including scientists, were simultaneously holding on to contradictory ideas (i.e. that earthly and heavenly matter are both similar and different). How was this possible? Bohm suggest that this has to do with a certain kind of "compartmentalization" of beliefs. The idea is that the mind protects itself from the need to change by putting contradicting ideas into different compartments, and in this way evades the challenge that new evidence may pose to prevailing and dearly held notions of universal order. As already emphasized, knowledge - or more precisely our set of beliefs - is not merely abstract but it involves forces (emotional, social etc.) that maintain the compartmentalization of ideas and allow us to hold on to our habitual frameworks of thought and notions of universal order. However, insight is a mental energy that can perceive and dissolve these forces.

Bohm suggests that we use the term insight to refer to the action of a general mental energy, which frees the mind of certain blocks in its accumulated set of beliefs. Such freedom then enables the ordinary faculties of the mind to have new modes of operations out of which flow particular insights. For example, in science it is the faculty of reason which can give rise to new concepts and theories, once the general action of insight has dissolved various blocks, as may have happened in the case of Newton.

At the end of his article Bohm considers insight in relation to education, underlining that education, too, needs to take into account the question of insight. What we ought to convey in education is the importance of constant passionate questioning of whatever is not clear. Moreover, one needs to question the questions. The idea is that the questions typically contain the presuppositions that are behind the confusion that leads us to ask questions in the first place:

“...it is necessary to sustain such questioning indefinitely, in spite of whatever difficulties ... one may encounter. This approach or attitude is what has to be communicated in education, that is, to be able to question ceaselessly, without any aggressive wish to demolish things but just simply because one sees that these things have to be questioned." (Bohm, 1981: 397)

However, Bohm goes on to emphasize that such questioning is not an end in itself, nor is its main purpose to produce answers. He rather sees ceaseless questioning as a precondition for a harmonious flow of life in general. The key point is to be free from contradictory and confused beliefs that limit the functioning of the mind. In other words, Bohm again emphasizes the importance of insight as a general mental energy, which enables particular insights to emerge through the faculties of the mind, such as reason and imagination.

In summary Bohm gives weight to the psychological factors that play a role in scientific and educational contexts. He emphasizes the emotional and social forces associated with our set of beliefs, forces which make it very difficult to perceive new things adequately and come up with relevant questions and new concepts and theories. The idea is, as we saw, that insight is a general psychological energy that acts to free the mind from the emotional and social forces, and thus enables it to operate in a new mode. Bohm assumes that when such freedom is present, it is possible to come up with radically new particular insights, reminiscent of Gestalt switches. The essence of the process of discovery for Bohm is not a rational, piecemeal working out of subsidiary questions to approach the answer to a big question, but rather a flash of perception where some basic new idea is born. After this, the task may then be to try to find various hypotheses that implement the idea in a quantitative way. Bohm's overall approach is quite in line with that of Krishnamurti, although Bohm does not discuss Krishnamurti in his 1981 article (but see Bohm and Peat, 2000).

As a comparison to a more Western approach we could mention that in their study of the process of inquiry the Finnish researchers Kai Hakkarainen and Matti Sintonen also acknowledge the role of the actual psychological situation of the inquirer. For example, they (2002: 40) point out how Sintonen in 1993 argued that

“...in actual problem-solving situations, an agent has to start generating questions and theories before all necessary information is available. In the interrogative process, initially very general, unspecified and "fuzzy" questions are transformed to a series of more specific questions. ... Theories are not conceived with full details at the outset, but must rather be developed from vague initial hunches."

Such "vague initial hunches" presumably also play a role in the process of insight, as understood by Bohm. For example, one might 
speculate that Newton had such hunches before he came up with his idea of universal gravitation. Hakkarainen and Sintonen further write:

"Being able to puzzle over an explanation-seeking question is uniquely human and points to a need to understand. Such understanding amounts, in part, to an ability to see connections between seemingly unconnected phenomena. (2002: 40-1)"

There are again psychological overtones in the puzzlement and the concomitant need to understand they refer to. Also, the idea that understanding involves seeing connections between what are thought to be unconnected phenomena resonates with Bohm's description of Newton's insight. Bohm emphasized the need to question everything that is not clear, which comes close to saying that we need to question things we are puzzled about and we do not understand.

\section{Conclusion}

In this article we have discussed some aspects of David Bohm's scientific and philosophical work, with the underlying purpose to detect some Eastern influences in it, in particular those resulting from his many discussions with the Indian thinker J. Krishnamurti. As Bohm rarely discussed Krishnamurti's views in his writings (though see Bohm and Peat, 2000), it is somewhat difficult to evaluate such influences in detail. However, it seems clear that there were significant influences. In particular, it seems that Bohm's encounter with Krishnamurti in the late 1950s played a significant role in helping Bohm to challenge his (dialectical) materialistic assumptions, thus opening up the possibility to develop the radical implicate order philosophy, and to re-interpret Bohm's 1952 theory in terms of the notion of active information. Also, it seems clear that Krishnamurti inspired Bohm to think about the nature of insight and to come up with suggestions that might help to facilitate insight in the process of inquiry and learning. One should also note that the interaction between Krishnamurti and Bohm was not without its problems, no doubt partly related to the very different thinking traditions with different epistemic criteria and practices they were coming from (for a thorough discussion of their interaction, see Peat, 1997). While we have not established any conclusive results in this study, we have given some reasons to believe that the interaction between Bohm and Krishnamurti is an example where Western scientific thinking was encouraged to move into new more comprehensive directions as a result of an encounter with the East.

\section{References}

Aspect, A., Grangier, P., Roger, G., 1982. Experimental test of Bell's inequalities using time-varying analyzers. Phys. Rev. Lett. 49, 1804-1807.

Atmanspacher, H., January 2014. 20th Century Variants of Dual-Aspect Thinking. Mind and Matter 12 (2), 245-288.

Bacciagaluppi, G., Valentini, A., 2009. Quantum Theory at a Crossroads: Reconsidering the 1927 Solvay Conference. Cambridge University Press, Cambridge.

Bell, J., 1987. Speakable and Unspeakable in Quantum Mechanics. Cambridge University Press, Cambridge.

Bohm, D., (KFA): A brief introduction to the work of Krishnamurti, Krishnamurti Foundation of America P.O. Box 1560, Ojai, CA 93023. https://ratical.org/many worlds/K/K1.html\#BohmIntro2K.

Bohm, D., 1951. Quantum Theory. Prentice Hall, Englewood Cliffs. Dover edition 1989.

Bohm, D., 1952. A suggested interpretation of the quantum theory in terms of "hidden variables" I and II. Phys. Rev. 85 (2), 166-179 and 180-193.

Bohm, D., 1957. Causality and Chance in Modern Physics. Routledge, London new edition with new preface 1984 .

Bohm, D., 1980a. Wholeness and the Implicate Order. Routledge, London.

Bohm, D., 1980b. On insight and its significance, for science, education and values. In: Epistemologia, vol. III, pp. 53-74 with Italian abstract. Originally published in Teacher's Coll. Rec. 80 (3), 1979, Birkbeck College, University of London.
Bohm, D., 1981. Insight, knowledge, science and human values. Teacher's Coll. Rec. 82 (3) 380-402.

Bohm, D., 1987. Hidden variables and the implicate order. In: Hiley, B.J., Peat, F.D. (Eds.), Quantum Implications: Essays in Honour of David Bohm. Routledge, London.

Bohm, D., 1989. Meaning and information. In: Pylkkänen, P. (Ed.), The Search for Meaning. Wellingborough, Crucible.

Bohm, D., 1990. A new theory of the relationship of mind and matter. Philos. Psychol. 3, 271-286.

Bohm, D., 1994. Thought as a System. Routledge, London.

Bohm, D., 1996. On Dialogue. Routledge, New York.

Bohm, D., Biederman, C., 1999. Bohm-Biederman Correspondence: Vol. 1 Creativity and Science. Routledge, London, edited by P. Pylkkänen.

Bohm, D., Edwards, M., 1991. Changing Consciousness: Exploring the Hidden Source of the Social, Political, and Environmental Crises Facing Our World. Harper, San Fransisco.

Bohm, D., Hiley, B.J., 1984. Measurement understood through the quantum potential approach. Found. Phys. 14 (3), 255-274.

Bohm, D., Hiley, B.J., 1987. An ontological basis for quantum theory: I. Non-relativistic Part. Syst. Phys. Rep. 144 (6), 323-348.

Bohm, D., Hiley, B.J., 1993. The Undivided Universe. An Ontological Interpretation of Quantum Theory. Routledge, London.

Bohm, D., Peat, F.D., 2000. Science, Order and Creativity 2nd Ed. Routledge, London. Bricmont, J., 2016. Making Sense of Quantum Mechanics. Springer, Berlin.

Brook, A., 1994. Kant and the Mind. Cambridge University Press, Cambridge.

Capra, F., 1995. The Tao of Physics. Boulder. Shambhala, Colorado.

Firestone, C., Scholl, B.J., 2016. Cognition does not affect perception: evaluating the evidence for 'top-down' effects. Behav. Brain Sci. 39.

Goldstein, S., 2013. Bohmian mechanics. In: Zalta, Edward N. (Ed.), The Stanford Encyclopedia of Philosophy (Spring 2013 Edition). http://plato.stanford.edu/ archives/spr2013/entries/qm-bohm/.

Hakkarainen, K., Sintonen, M., 2002. The interrogative model of inquiry and computer-supported collaborative learning. Sci. Educ. 11, 25-43.

Hanson, N.R., 1958. Patterns of Discovery. Cambridge University Press, Cambridge.

Hiley, B.J., Pylkkänen, P., 2005. Can mind affect matter via active information? Mind Matter 3 (2), 7-26. http://www.mindmatter.de/resources/pdf/hileywww.pdf.

Hintikka, J., 1999. Is logic the key to all good reasoning? In: Hintikka, J. (Ed.), Selected Papers, Inquiry as Inquiry:A Logic for Scientific Discovery, vol. 5. Kluwer, Dordrecht, pp. 1-24.

Holland, P., 2011. A quantum of history. Contemp. Phys. 52, 355.

Isaacs, W. 1999. Dialogue and the Art of Thinking Together: a Pioneering Approach to Communicating in Business and in Life. Bantam Doubleday Dell Publishing Group.

Jammer, M., 1988. David Bohm and his work: on the occasion of his seventieth birthday. Found. Phys. 18, 691-699.

Krishnamurti, J., 1954. The First and Last Freedom. Gollanz, London.

Krishnamurti, J., Bohm, D., 1999. The Limits of Thought. Routledge, London.

Ladyman, J. and, Ross, D., 2007. In: Every Thing Must Go: Metaphysics Naturalized. Oxford University Press, Oxford (with D. Spurrett and J. Collier).

Maleeh, R., Amani, P., 2012. Bohm's theory of the relationship of mind and matter revisited. Neuroquantology 10, 150-163.

Peat, D., 1997. Infinite Potential: the Life and Times of David Bohm. Paperback edition with a new afterword by the author. Basic books, New York.

Pylkkänen P., A quantum cure for panphobia, (forthcoming), In: Seager W., (Ed), Routledge Handbook of Panpsychism, Routledge; London.

Pylkkänen, P., 2007a. Mind, Matter and the Implicate Order. Springer Frontiers Collection, Heidelberg and New York.

Pylkkänen, P., 2007b. Escaping the prison of language. In: Ahlsén, E., et al. (Eds.), Communication - Action - Meaning: a Festschrift to Jens Allwood. Göteborg University, pp. 149-155.

Pylkkänen, P., 2014. Can quantum analogies help us to understand the process of thought? Mind Matter 12 (1), 61-91. http://www.mindmatter.de/resources/ pdf/pylkkaenen_. www.pdf.

Pylkkänen, P., 2015. The quantum epoché. Prog. Biophysics Mol. Biol. 119 (3), $332-340$

Pylkkänen, P., 2017a. Is there room in quantum ontology for a genuine causal role of consciousness? In: Khrennikov, A., Haven, E. (Eds.), The Palgrave Handbook of Quantum Models in Social Science. Palgrave Macmillan, London.

Pylkkänen, P., 2017b. The crisis of intelligibility in physics and the prospects of a new form of scientific rationality. In: Niiniluoto, I., Wallgren, T. (Eds.), On the Human Condition: Philosophical Essays in Honour of the Centennial Anniversary of Georg Henrik von Wright. Acta Philosophica Fennica, vol. 93. The Philosophical Society of Finland, Helsinki.

Pylkkänen, P., Hiley, B.J., Pättiniemi, I., 2016. Bohm's approach and individuality. In: Guay, A., Pradeu, T. (Eds.), Individuals across the Sciences. Oxford University Press, Oxford. http://arxiv.org/abs/1405.4772.

Schaffer, J., 2003. Is there a fundamental level? Noûs 37 (3), 498-517.

Schaffer, J., 2010. Monism: the priority of the whole. Philos. Rev. 119 (1), 31-76.

Seager, W., 2013. Classical levels, Russellian monism and the implicate order. Found. Phys. 43, 548-567.

Seager, W., Allen-Hermanson, S., 2015. Panpsychism. In: Zalta, Edward N. (Ed.), The Stanford Encyclopedia of Philosophy (Fall 2015 Edition). https://plato.stanford. edu/archives/fall2015/entries/panpsychism/.

Senge, P.M., 2006. The Fifth Discipline: the Art and Practice of the Learning Organization. Doubleday. 
Sintonen, M., 1990. How to put questions to nature. In: Knowles, D. (Ed.), Explanation and its Limits. Cambridge University Press, Cambridge.

Sintonen, M., 1993. In search of explanations: from why-questions to Shakespearean questions. Philosophica 51, 55-81.

Stamenov, M., 2004. The rheomode of language of David Bohm as a way to reconstruct the access to physical reality. In: Globus, G., Pribram, K., Vitiello, G. (Eds.), Being and Brain. At the Boundary between Science, Philosophy, Language and Arts, Advances in Consciousness Research, vol. 58. John Benjamins, Amsterdam, pp. 167-197.

Sternberg, R.J., Davidson, Janet E. (Eds.), 1996. The Nature of Insight, Reprint. ed. The MIT Press, Cambridge, MA; London.

Strawson, Galen, 2006a. Realistic monism - why physicalism entails panpsychism. J. Conscious. Stud. 13 (10-11), 3-31.

Strawson, Galen, 2006b. Panpsychism? Reply to commentators with a celebration of Descartes. J. Conscious. Stud. 13 (10-11), 184-280.
Walleczek, J., Grössing, G., 2016. Nonlocal quantum information transfer without superluminal signalling and communication. Found. Phys, 46 (9), 1208-1228.

Wang, Z., Busemeyer, J.R., Atmanspacher, H., Pothos, E.M., 2013. The potential of using quantum theory to build models of cognition. Top. Cognitive Sci. 5 , 672-688.

Weber, R., 1987. Meaning as being in the implicate order philosophy of David Bohm: a conversation. In: Hiley, B.J., Peat, F.D. (Eds.), Quantum Implications: Essays in Honour of David Bohm. Routledge, London.

Wendt, A., 2015. Quantum Mind and Social Science: Unifying Physical and Social Ontology. Cambridge University Press, Cambridge.

Wheeler, John A., 1990. Information, physics, quantum: the search for links. In: Zurek, W.H. (Ed.), Complexity, Entropy, and the Physics of Information. Addison-Wesley, Redwood City, California.

von Wright, G.H., 1989. Images of science and forms of rationality. In: Doorman, S.J. (Ed.), Images of Science: Scientific Practise and the Public. Aldershot: Gower.

Please cite this article in press as: Pylkkänen, P., The role of Eastern approaches in David Bohm's scientific-philosophical odysseia, Progress in Biophysics and Molecular Biology (2017), http://dx.doi.org/10.1016/j.pbiomolbio.2017.08.015 